\title{
Jole
}

\section{STRENGTHENING COLLEGE STUDENTS' CONFIDENCE IN THEIR ETHICAL REASONING ABILITY}

\begin{abstract}
The purpose of this longitudinal study was to examine if participation in a four-year ethics curriculum strengthened college students' confidence in their own ethical reasoning ability. A longitudinal cohort of college students was followed over four years from their freshman $(n=779)$ to senior year $(n=545)$. Students' confidence in their own ethical reasoning abilities were assessed before and after completion of the curriculum with results indicating an increase in students' confidence.
\end{abstract}

Keywords: college student ethics, ethics and leadership education, ethical reasoning, ethics curriculum

\section{Introduction}

Even a quick survey of recent higher education headlines reveals that some of today's college students on a wide array of campuses have encountered challenges in ethical reasoning. Ethical reasoning skills entail students assessing their ethical values and considering how differing ethical perspectives and contexts can be leveraged to better understand and resolve ethical dilemmas (Association of American Colleges and Universities [AAC\&U], 2009). The research literature shows that awareness of these ethical challenges is not sufficient preparation and that college students must be taught the skills to make ethical decisions (Cooper, 2007; Poff, 2007). The Association of American Colleges and Universities' (AAC\&U) Liberal Education and America's Promise (LEAP) national public advocacy initiative identifies ethical reasoning skills as an essential learning outcome of college attendance (AAC\&U, 2007; AAC\&U,
2009). AAC\&U's research also indicates that a majority of employers want colleges and universities to place more emphasis on the development of values and ethics (AAC\&U, 2007; Hart, 2018). Dalton et al. (2004) asserts that colleges and universities are increasingly willing to focus on ethics and character education due to impacts success brings in enhancing society, gaining the interest of legislators and accreditors, recruiting other students, and improving the campus environment.

The purpose of this longitudinal study was to examine if participation in a four-year ethics curriculum strengthened students' confidence in their own ethical reasoning abilities. Improving college student confidence in their own skills and abilities plays an important role in increasing engagement and retention (Meer \& Chapman, 2014). Results from this research study may provide impactful insights for higher education institutions that are engaged 
in ethical reasoning skill development, moral and civic education, character education, and student leadership development. Specifically, the research study focuses upon two overarching research questions. First, does participation in a four-year ethics curriculum strengthen how traditional-aged students assess their ethical reasoning skills? Second, does participation in a four-year ethical reasoning curriculum influence students' confidence in their ability to apply an ethical decision-making process?

\section{Four-Year Ethical Reasoning Curriculum}

During the 2016-2017 academic year, a public master's level comprehensive college in the southern region of the United States implemented a fouryear ethics curriculum for incoming undergraduate students in all academic majors. The curriculum's learning outcomes were created through robust faculty discussions, use of ethical reasoning literature reviews, and integration of AAC\&U's Ethical Reasoning essential learning outcomes. The curricular student learning outcomes (SLOs) for the four-year ethics curriculum are as follows:

- SLO \#1: Students will be able to identify concepts such as ethics, morals, character, ethical principles, and ethical relativism.

- SLO \#2: Students will be able to identify core values and describe the connection between values and ethical reasoning.

- SLO \#3: Students will be able to describe the impact of ethics on a profession or academic discipline.

- SLO \#4: When describing an ethical issue, students will correctly differentiate if it is a moral temptation or an ethical dilemma.

- SLO \#5: Students will be able to apply the ethical reasoning process to an ethical dilemma from their own experience.

- SLO \#6: Students will report that they believe ethical reasoning skills are an important component of being a principled leader.
- SLO \#7: Students will report increased confidence in their ability to apply the ethical reasoning process.

The student learning outcomes were delivered through a new four-year intentionally designed ethics curriculum embedded in existing courses, which were revised to integrate the ethics content, involving students in all classes and academic majors. The curriculum included ethics instruction in a sequence of five required courses. The freshmen experience seminar was redesigned to include five class sessions focusing on the introduction of key ethical reasoning concepts (SLO \#1) and work in small groups to explore one of 10 ethics scenarios related to the impact of ethics on a profession (SLO \#3). In a freshmen ethics seminar, students learned an ethical reasoning model, practiced differentiating ethical dilemmas from moral temptations (SLO \#4), and applied an ethical reasoning process to resolve an ethical dilemma (SLO \#5) using four paradigms and decision making principles from Kidder's (2009) book, How Good People Make Tough Choices: Resolving the Dilemmas of Ethical Living. The sophomore leadership seminar redesigned three ethical reasoning class sessions focusing on the connection between values and ethics (SLO \#2). The junior leadership seminar focused on ethical reasoning dilemma resolution (SLO \#4 and SLO \#5) and developing the moral courage to act in congruence with their values and ethics. The senior leadership seminar provided additional focus on ethics in the professions (SLO \#3) and the application of an ethical reasoning process (SLO \#5).

\section{Methods and Materials}

This study utilized a quantitative methodological approach to assess students' confidence in their own ethical reasoning abilities. A descriptive survey research technique was employed that mirrored the curriculum's learning outcomes, helping to ensure both content validity and reliability of the survey instrumentation over time. This methodology was most advantageous to the research due to the focus of descriptive research surveys on gaining insight into individual's perceptions and beliefs 
about an experience (Lodico et al., 2006). This focus was especially valuable in using the same survey before and after a longitudinal cohort experienced a comprehensive four-year ethical reasoning curriculum.

\section{Survey Instrumentation}

This research study utilized a survey instrument designed to measure student confidence in their own ethical reasoning skills and abilities as well as their confidence level in applying an ethical reasoning process. The instrument was administered as a pretest/post-test to assess growth over time, before and after implementation of a four-year ethical reasoning curriculum. The survey questions, listed in Table 1, were designed to mirror the learning outcomes of the four-year ethics curriculum in order to ensure content validity. Two content experts also participated in the validation of the survey instrument, including a faculty member specializing in ethics curricula and a faculty member who specializes in character education and ethical problem-solving. Feedback from both content experts was incorporated in the final draft of the survey instrument.

\section{Table 1}

Longitudinal Cohort Respondents Who Strongly Agree or Agree with Survey Questions

\begin{tabular}{|c|c|c|c|}
\hline Survey Question & $\begin{array}{l}\% \text { of } 2016 \\
\text { freshmen }\end{array}$ & $\begin{array}{l}\% \text { of } 2019 \\
\text { seniors }\end{array}$ & $\begin{array}{l}\% \\
\text { change }\end{array}$ \\
\hline \multicolumn{4}{|l|}{ Cognitive Learning Outcomes } \\
\hline $\begin{array}{l}\text { I am able to identify concepts such as ethics, morals, character, } \\
\text { ethical principles, and ethical relativism. (SLO 1) }\end{array}$ & 81.8 & 96.7 & +14.9 \\
\hline $\begin{array}{l}\text { I am able to identify core values and describe the connection } \\
\text { between values and ethical reasoning. (SLO 2) }\end{array}$ & 82.4 & 96.7 & +14.3 \\
\hline $\begin{array}{l}\text { I am able to describe the impact of ethics on a profession or } \\
\text { academic discipline. (SLO 3) }\end{array}$ & 79.1 & 95.7 & +16.6 \\
\hline $\begin{array}{l}\text { When describing an ethical issue, I am able to correctly } \\
\text { differentiate whether it is a moral temptation or an ethical } \\
\text { dilemma. (SLO 4) }\end{array}$ & 59.8 & 93.5 & +33.7 \\
\hline $\begin{array}{l}\text { I am able to apply the ethical reasoning process to an ethical } \\
\text { dilemma from my own experience. (SLO 5) }\end{array}$ & 72.7 & 95.2 & +22.5 \\
\hline Cognitive Learning Outcomes Average & 75.2 & 95.6 & +20.4 \\
\hline \multicolumn{4}{|l|}{ Attitudinal Learning Outcomes } \\
\hline $\begin{array}{l}\text { I believe that ethical reasoning skills are an important component } \\
\text { of being a principled leader. (SLO 6) }\end{array}$ & 95.5 & 96.2 & +0.7 \\
\hline $\begin{array}{l}\text { I am confident in my ability to apply an ethical reasoning process } \\
\text { to solve complex ethical dilemmas. (SLO 7) }\end{array}$ & 88.8 & 96.5 & +7.7 \\
\hline
\end{tabular}


The survey operationalized the learning outcomes by changing each statement to first-person and applying a five-point-Likert scale, which is presented in Table 1. For each survey question, students were asked to rate their own ethical reasoning skills and abilities as well as their confidence level in applying the ethical reasoning process. The five-point Likert scale ranged from 1 (strongly disagree) to 5 (strongly agree). During freshmen experience seminars, students assessed their confidence level and perceptions about their own ethical reasoning skills. Four years later during senior leadership seminars, those same students remaining in the cohort participated in the identical assessment they completed as freshmen during their senior leadership seminar.

\section{Survey Procedure}

During freshmen experience seminars, students were invited to participate in a short survey assessing their confidence level and perceptions about their own ethical reasoning skills and abilities. Students were provided with an anonymous link to the webbased survey instrument. Follow-up reminders were deployed in weekly increments online and inclass throughout the first month of the freshmen seminar, encouraging survey participation. Four years later during senior leadership seminars, those same students remaining in the cohort were invited to participate in the identical survey they completed as freshmen during their senior leadership seminar. Two reminders were deployed online and in-class during the senior leadership seminar to encourage survey completion.

\section{Participants}

Participants in this study included a longitudinal cohort of traditional-aged college students from a master's granting comprehensive public institution in the southeast United States. The participants consisted of 779 incoming freshmen who completed the survey before participating in the ethics curriculum and 545 seniors who completed the same survey four years later after completing the four-year ethics curriculum. The study participants were predominantly enrolled full-time, resided in on- campus housing, and were representative of the wide array of academic majors offered by the institution. Students from underrepresented minority groups represented $26 \%$ of the freshmen and $24 \%$ of the seniors in the cohort.

\section{Data Analysis}

This longitudinal study examined if participation in a four-year ethics curriculum strengthened college students' confidence in their own ethical reasoning ability. The study analyzed the results from a seven question pre-test/post-test to assess growth over time, before and after implementation of a four-year ethical reasoning curriculum. The survey employed a five-point-Likert scale, which ranged from 1 (strongly disagree) to 5 (strongly agree).

Given the different number of freshmen $(n=779)$ completing the pre-test compared to seniors $(n=545)$ completing the post-test due to attrition over the four years of the longitudinal study, data analysis included comparing the mean number of respondents indicating strongly agree and agree on the pre-test and post-test for each of the seven survey questions. An independent t-test using the mean scores on the pre-test and post-test for each of the survey questions was then conducted, controlling for the differing number of respondents and standard deviation. Independent t-test results for each of five cognitive learning outcomes showed statistically significant growth. The percentage mean growth for each learning outcome is listed in Table 1.

\section{Results}

Table 1 presents the descriptive statistics for the responses of the longitudinal cohort of students to the seven survey questions. As demonstrated in the table, significant growth was reported by students in each of the five cognitive learning outcome domains. Students reported a $14.9 \%$ growth (from $81.8 \%$ to $96.7 \%$ ) in their ability to identify concepts such as ethics, morals, character, ethical principles, and ethical relativism between their freshmen and senior year. Students also reported a $14.3 \%$ growth (from $82.4 \%$ to $96.7 \%$ ) in their ability to describe the connection between values and ethical reasoning 
over their four years in college. Similar growth of $16.6 \%$ (from $79.1 \%$ to $95.7 \%$ ) was also reported by students in their ability to describe the impact of ethics on a profession or their academic discipline.

The largest gains reported by students were in their ability to correctly differentiate between a moral temptation or ethical dilemma, with a $33.7 \%$ reported increase (from 59.8\% to 93.5\%). The second largest gain, $22.5 \%$ growth over four years (from $72.7 \%$ to $95.2 \%$ ), was reported by students in their ability to apply an ethical reasoning process to an ethical dilemma from their own experience. Assessment data from the year before the new ethical reasoning curriculum was implemented indicated that $73 \%$ of seniors reported the ability to apply an ethical reasoning process, which was more than $22 \%$ lower than the rates after implementation of the ethics curriculum.

In addition to the five cognitive learning outcomes, the survey also posed two attitudinal outcome domains. Despite freshmen ratings of these attitudinal outcomes related to leadership and confidence being rated among the highest in the study, 95.5\% and $88.8 \%$ respectively, an increase over time was still indicated. Senior students reported a slight increase of approximately $1 \%$ in their affirmation that ethical reasoning skills are an important component of being a principled leader (from $95.5 \%$ to $96.2 \%$ ) as well as a $7.7 \%$ increase ( $88.8 \%$ to $96.5 \%$ ) in confidence in applying an ethical reasoning process to solve complex ethical dilemmas.

\section{Discussion}

Formal instruction and curricula in ethics and the application of an ethical reasoning decision-making process is increasingly being recognized as a critical component of a college education and has received greater focus by faculty, leadership development educators, student affairs professionals, and administrators in colleges and universities. Improving college student confidence in their own skills and abilities is important in increasing engagement and retention (Meer \& Chapman, 2014). Sample (2009) and Sternberg (2010) assert that college campuses provide an especially valuable learning laboratory where ethics can be developed. Research on student development theory, as well as how college affects students, also indicates that most students navigate substantial growth and development based on new knowledge, situations and issues encountered during the college years (Mayhew et al., 2016; Pascarella \& Terenzini, 2005; Dalton et al., 2004), which suggests that college is a powerful environment for learning and practicing ethical reasoning decision-making processes. The findings associated with each research question in this study are consistent with the research literature.

\section{Research Question 1}

The first research question asked, does participation in a four-year ethical reasoning curriculum strengthen how traditional-aged students assess their ethical reasoning skills? Results from the survey supported the hypothesis that participation in a four-year ethical reasoning curriculum strengthens how traditionalaged students assess their own ethical reasoning skills. In addition to students reporting growth in all five ethical reasoning learning outcome areas, the reported growth was substantial, averaging a $20.4 \%$ growth. The growth ranged from $14.3 \%$ to $33.7 \%$. The largest gains reported by students were in areas where they likely experienced new concepts in the instruction. Instruction associated with their ability to correctly differentiate between a moral temptation or ethical dilemma, with a $33.7 \%$ reported increase (from 59.8\% to 93.5\%). The second largest gain, $22.5 \%$ growth over four years (from $72.7 \%$ to $95.2 \%$ ), was reported by students in their ability to apply an ethical reasoning process to an ethical dilemma from their own experience.

\section{Research Question 2}

The second research question asked, does participation in a four-year ethical reasoning curriculum influence students' confidence in their ability to apply an ethical decision-making process? While the cognitive student learning outcomes examined in this study yielded an average growth of $20.4 \%$, the two attitudinal outcomes yielded $4.2 \%$ growth over this same time period. It is important to note that despite freshmen ratings of attitudinal outcomes related to leadership and confidence being rated among the highest in the study, 95.5\% and $88.8 \%$ respectively, the results still indicated an 
increase over time in these areas, including a $7.7 \%$ increase (88.8\% to $96.5 \%)$ in confidence in applying an ethical reasoning process to solve complex ethical dilemmas. There are several possible explanations for this finding, including that the scores on the attitudinal learning outcomes started $17 \%$ higher on average than the cognitive learning outcomes. A second explanation may be that students gained a greater appreciation and understanding of the complexities involved in ethical reasoning after participating in the four-year curriculum. This explanation is consistent with student development theory.

Student development theory can be particularly helpful in contextualizing growth in college students' ethical reasoning skills and confidence in their own ability to apply an ethical reasoning decision-making process. Cognitive-structural student development theories, like Perry's theory of intellectual and ethical development, offer a framework for examining ethical reasoning growth as well as student perception and confidence about their own abilities (Evans et al., 2016). This theory helps explain the transition from dualism, where students look to others for answers or a sense of authority, to commitment and confidence through a series of developmental "positions" (Perry, 1998; Evans et al., 2016).

\section{Implications for Leadership Education and Student Affairs Practice}

Ethical reasoning skills are widely recognized as an essential student learning outcome in higher education by both student affairs professionals and faculty (AAC\&U, 2007). This common recognition of the importance of helping students develop stronger ethical reasoning skills provides a rich opportunity for strengthening student affairs and academic affairs collaborations, and it provides fertile ground for innovative practices in leadership education. Leadership development educators and student affairs professionals can be especially impactful in developing and fostering ethical learning environments in student life through ethical modeling and demonstrating effective relational leadership (Reybold et al., 2008). The findings from this study suggest several key implications for innovative leadership education initiatives, including continued expansion of the student affairs role as instructional partners in the classroom and cocurricular experience, as well as extending how student engagement is viewed through the lens of reinforcing students' ability to make meaningful leadership and ethics connections between academic and student life learning environments.

Study results indicated participation in a four-year ethics curriculum strengthened how traditionalaged students assess their ethical reasoning skills. Consistent with the ACPA-College Student Educators International (ACPA) and NASPA-Student Affairs Administrators in Higher Education (NASPA) Competency Areas for Student Affairs Educators, student affairs professionals were active partners in the delivery of this four-year curriculum, serving as instructors in some of the first-year experience courses and leadership seminars where the ethical reasoning curriculum was delivered (ACPA \& NASPA, 2015). The instructional content associated with ethical reasoning skills in this study was particularly applicable to student affairs competency domains given the synergy with moral and ethical student development theories, leadership development, focus on learning and development, as well as the insights student affairs professionals gain through the experience of helping college students navigate challenging ethical dilemmas in the course of their daily work with students.

Research on how college affects students and student development theory indicates that college students grow as they develop new knowledge and encounter new situations and issues (Mayhew et al., 2016; Pascarella \& Terenzini, 2005; Dalton et al., 2004), which suggests the co-curricular learning environment provides a rich landscape for practicing ethical reasoning decision-making processes. Leadership educators are well-positioned to foster these continuous learning opportunities through programming and creating opportunities for students to consider how ethical reasoning and decision-making can be applied within a wide array of career and academic environments, as well as through student affairs functional areas including residence life, student clubs and activities, and student leadership programs. 
Improving college student confidence in their own skills and abilities is important in increasing student engagement and retention in college (Meer \& Chapman, 2014). Additionally, students' ethical self-identity develops as they analyze ethical issues and practice ethical decision-making (AAC\&U, 2009). Young et al. (2019) provide an insightful discussion of the requisite conditions necessary for fostering engagement and a feeling of connection among students within campus learning environments that extends beyond traditional discussions of student engagement by taking a broad view of the diverse ways in which engagement and connection is internalized and operationalized by student. Broadening the way leadership education is currently conceptualized within higher education and coupling it with student professional development and career and cocurricular mentoring can provide opportunities to partner with faculty to build leadership connections between student life and academic content (Young et al., 2019).

\section{Study Limitations and Future Research Recommendations}

An analysis of the study's sampling procedures and methodology indicates several potential limitations. The study was conducted at one higher education institution, and the characteristics of the sample may limit the extent to which the results can be generalized to other institutions and types of students. For example, the participants were primarily traditional-aged, full-time students in a residential college setting. Therefore, the results may not be generalizable to other campus environments. Future research studies incorporating multiple institutions and a more diverse sample of non-traditional aged students may improve the ability to generalize the findings. An additional limitation of the study is the use of survey methodology, an indirect assessment method, to investigate students' ethical reasoning skills and level of confidence in applying an ethical reasoning decision-making process. Future research studies employing direct assessment methods will help provide a more holistic view of learning outcome attainment.

\section{Conclusions}

The research literature asserts that ethics instruction must extend beyond ethical issue identification to include practice in ethical reasoning and actually making ethical decisions (Cooper, 2007; Poff, 2007). Ethical reasoning curricula provides a domain of study that fosters students' abilities to evaluate their own values and beliefs, think critically about ethical issues, and apply an ethical reasoning process to generate sound decisions. The findings from this research study suggest that multi-year participation in formal ethical reasoning curricula exerts significant influence on increasing how traditional-aged students' rate their ethical reasoning skills as well as their own confidence in applying ethical reasoning decision-making processes. Meer and Chapman (2014) assert increasing college student confidence and feelings of competence is a key component in increasing retention and student engagement in college. 


\section{References}

ACPA-College Student Educators International and NASPA-Student Affairs Administrators in Higher Education (2015). ACPA/NASPA Professional Competency Areas for Student Affairs Educators. ACPA/ NASPA. Retrieved from https://www.naspa.org/images/uploads/main/ACPA_NASPA_Professional_ Competencies_FINAL.pdf

Association of American Colleges and Universities. (2007). College Learning for the New Global Century. AAC\&U. Retrieved from http://www.aacu.org/leap/documents/GlobalCentury_final.pdf

Association of American Colleges and Universities (AAC\&U). (2009). Ethical Reasoning VALUE Rubric. Retrieved from https://www.aacu.org/ethical-reasoning-value-rubric

Cooper, M. (2007). Are we sending mixed messages? How philosophical naturalism erodes ethical instruction. Journal of Business Ethics, 75(2), 171-180.

Dalton, J. C., Russell, T. R., \& Kline, S. (2004). Assessing Character Outcomes in College (New Directions for Institutional Research Report No. 122). Jossey-Bass.

Evans, N., Forney, D., Guido-DeBrito, F., Renn, K., \& Patton, L. (2016). Student Development in College: Theory, Research \& Practice (3rd ed.). Jossey-Bass.

Hart, P. D. (2018). How Should Colleges Prepare Students To Succeed In Today's Global Economy? Retrieved from http://www.aacu.org/leap/documents/LEAP_MakingtheCase_Final.pdf

Kidder, R. M. (2009). How good people make tough choices: Resolving the dilemmas of ethical living. Harper.

Lodico, M. G., Spaulding, D. T., \& Voegtle, K. H. (2006). Methods in Educational Research: From Theory to Practice. Jossey-Bass.

Mayhew, M. J., Rockenbach, A. N., Bowman, N. A., Seifert, T. A., Wolniak, G. C., Pascarella, E. T., \& Terenzini, P. T. (2016). How College Affects Students: $21^{\text {st }}$ Century Evidence that Higher Education Works (3rd ed). JosseyBass.

Meer, N. M., \& Chapman, A. (2014). Assessment for Confidence: Exploring the Impact that Low-Stakes Assessment Design has on Student Retention. International Journal of Management Education, 12(2), 186-192.

Pascarella, E. T., \& Terenzini, P. T. (2005). How College Affects Students: A Third Decade of Research. Jossey-Bass.

Perry, W. (1998). Forms of ethical and intellectual development in the college years: A scheme. Jossey-Bass.

Poff, D. C. (2007). Duties owed in serving students: The importance of teaching moral reasoning and theories of ethical leadership in educating business students. Journal of Academic Ethics, 5(1), 25-31.

Reybold, L. E., Halx, M. D., \& Jimenez, A.L. (2008). Professional Integrity in Higher Education: A Study of Administrative Staff Ethics in Student Affairs. Journal of College Student Development, 49(2), 110124. 
Sample, S. B. (2009). The pursuit of wisdom: A modest, but essential, prescription for the future. Innovations in Higher Education, 35, 79-89.

Sternberg, R. J. (2010). Teaching for ethical reasoning in liberal education. Liberal Education, 96(3), 32-37.

Young, N. D., Michael, C. N., \& Smolinksi, J. A. (2019). Captivating Campuses: Proven Practices that Promote College Student Persistence, Engagement, and Success. Vernon Press. 